\title{
BUILDING RENEWAL: THE CENTRALITY OF EVENTUAL OCCUPANCY IN DESIGN DECISIONS
}

\author{
CORDELIA O. OSASONA \\ Department of Architecture, Obafemi Awolowo University, Nigeria
}

\begin{abstract}
Architectural renewal, otherwise termed "adaptive re-use", has long established its efficacy as a more effective way of justifying the continued existence of heritage structures, than mere restoration. Ile-Ife, though not particularly indicated in architectural heritage conservation in Nigeria, has its own share of such buildings worthy of conservation. Adopting a comparative case-study approach, two renewal projects in Ile-Ife are critiqued - with a view to highlighting the centrality of the role eventual tenancy played in their design proposals. In each case, an old family house was commissioned for renewal: one to be used, thereafter, only by blood relatives; the other, essentially to be let out to paying tenants. Specifically, Lokore House underwent renewal to give modern accommodation to members of an extended family; on the other hand, Agbedegbede House, was to be put up for rent (with a few rooms reserved for other extended family members). While the former was executed on a fairly liberal budget, the latter was to be "shoe-string". In articulating the latter mandate, prime consideration was given to communal spaces being perfunctory (since not carrying a need for family-bonding); maintaining as much of the existing building as was still structurally sound; ensuring ease of circulation in common spaces and specifying rugged finishes. Inflation that set in since the Lokore House project (2018-2019) has accounted for higher prices of similar materials for the Agbedegbede one (started in 2020 and still ongoing). This notwithstanding, the major constraint of making the intervention comparatively lowbudget is being met. In both cases, client and architect remained constant. Despite this (and also the fact that the end-use was still residential, and in similar cultural and physical neighbourhoods), a comparative analysis shows that it was the issue of clearly distinguishable variance in eventual occupancy that dominated design decisions.
\end{abstract}

Keywords: Lokore, adaptive re-use, Agbedegbede, tenancy, building renewal.

\section{INTRODUCTION}

Despite the fast-paced nature of modern living (and the increasing premium placed on the value of land), the conservation of architectural monuments will forever be topical. This is so for a variety of reasons, which include: a fundamental human psychological need for anchorage with the past; visual relief, akin to serendipity, some such monuments provide; alternative accommodation (in places of urban residential stress), and the real economic benefits of architecture-based tourism [1], [2].

With these established bases for the phenomenon, architectural conservation (encompassing restoration and renewal) is a highly advanced practice in the West [3]. In much of Africa, this is not so; specifically, in Nigeria, the practice is virtually non-existent. Even the tentative steps taken by environmental-interest groups (such as LEGACY), have not only been met with indifference on the part of government; recently, a major undertaking by LEGACY was frustrated - and eventually demolished outright [4], [5]. In light of the prevalent governmental neglect, it should not be surprising that corporate organisations in Nigeria also, generally, do not see the need to get involved. Nevertheless, some such concerns - coupled with private individuals - by virtue of international exposure and financial wherewithal, have gradually seen it as their corporate social responsibility, on the one hand, and their family duty, on the other, to try and salvage specific buildings in the local landscape of perishing architectural heritage. LEGACY has even compiled a compendium of such [6]. 
Stemming from this awakening, the Nigerian Institute of Architects (NIA) recently established a Heritage Architecture Committee, with the mandate to identify and recommend for conservation-restoration, heritage buildings worthy of such intervention in the six geopolitical zones of the country. Expectedly, this is with a view to initiating (and superintending) such conservation exercises. Similarly - but less dramatically - in Ile-Ife, for instance, certain individuals have risen to the challenge of not just restoring decrepit family houses "for posterity"; the interest of the initiators of these schemes has majorly been that these houses also serve living members of their extended families, now, as comfortable, modern-day accommodation.

The present work highlights two projects in Ile-Ife, executed in the spirit of the latter orientation. The first (Lokore House) was the focus of a previous publication [7]. It features in the present discourse as a comparative case-study with Agbegbede House, the main focus of this work; this is with a view to emphasising the salient points of departure. The appropriateness of this approach was informed by the fact that original use, cultural/neighbourhood context, client and project architect are the same in both adaptive reuse schemes. Details of the essentials of the comparative analysis are set out in Table 1.

\section{THE BACKGROUND}

Both the Lokore (Odeyemi Family) House and the Agbedegbede House are landed property to which the sponsor of their renewal, Chief John Agboola Odeyemi, is tied by birth. The Lokore House was his paternal grandfather's home, while that at Agbedegbede was his maternal grandmother's. Chief Odeyemi himself is a well-travelled professional, fully conversant with what subsists in developed parts of the world, with respect to valuable architectural legacies. In 2018, based on his emotional attachment to the Lokore (Odeyemi Family) House - where he had spent a substantial part of his childhood - he sought architectural expertise in upgrading the property to a more modern residence. The beneficiaries were to be his sister (who was currently resident in the house) and other members of the extended family who would later join her.

In 2020, based on the success of the adaptive reuse intervention on the Lokore House, Chief Odeyemi decided to similarly sponsor renewal for the Agbedegbede House. (Significantly, on the occasion of the "unveiling" of the new-look Odeyemi Family House, the French Ambassador, Monsieur Jerome Pasquier, who was on an official visit to the Obafemi Awolowo University, decided to grace the occasion - having heard about the complete transformation that had overtaken the building; see Figs 1 and 2). In this new enterprise, Chief Odeyemi decided to maintain the services of the architect he had used previously - for reasons of continuity, as evidence of his confidence in services previously rendered, and as an overall endorsement. The project kicked off in September, and is still underway.

\section{THE GENERAL MANDATE}

While the Lokore project had been exclusively for the comfort of family, the new scheme at Agbedegbede was to, essentially, provide good quality rentable single-room, and "room-andparlour" accommodation. On the Lokore (Odeyemi) project, the client had been content to invest whatever it would take to transform the building into a well-lit, well-aerated residence with modern conveniences and furnishing - to the extent to which the cultural background and general social orientations of the end-users could cope with such facilities. In essence, a fairly liberal budget. For Agbedegbede, there was to be no furniture, and all amenities were to be spartan - merely utilitarian and durable. A major restriction in fulfilling this latter mandate was that it was not expedient to bring down existing walls - at least not for 


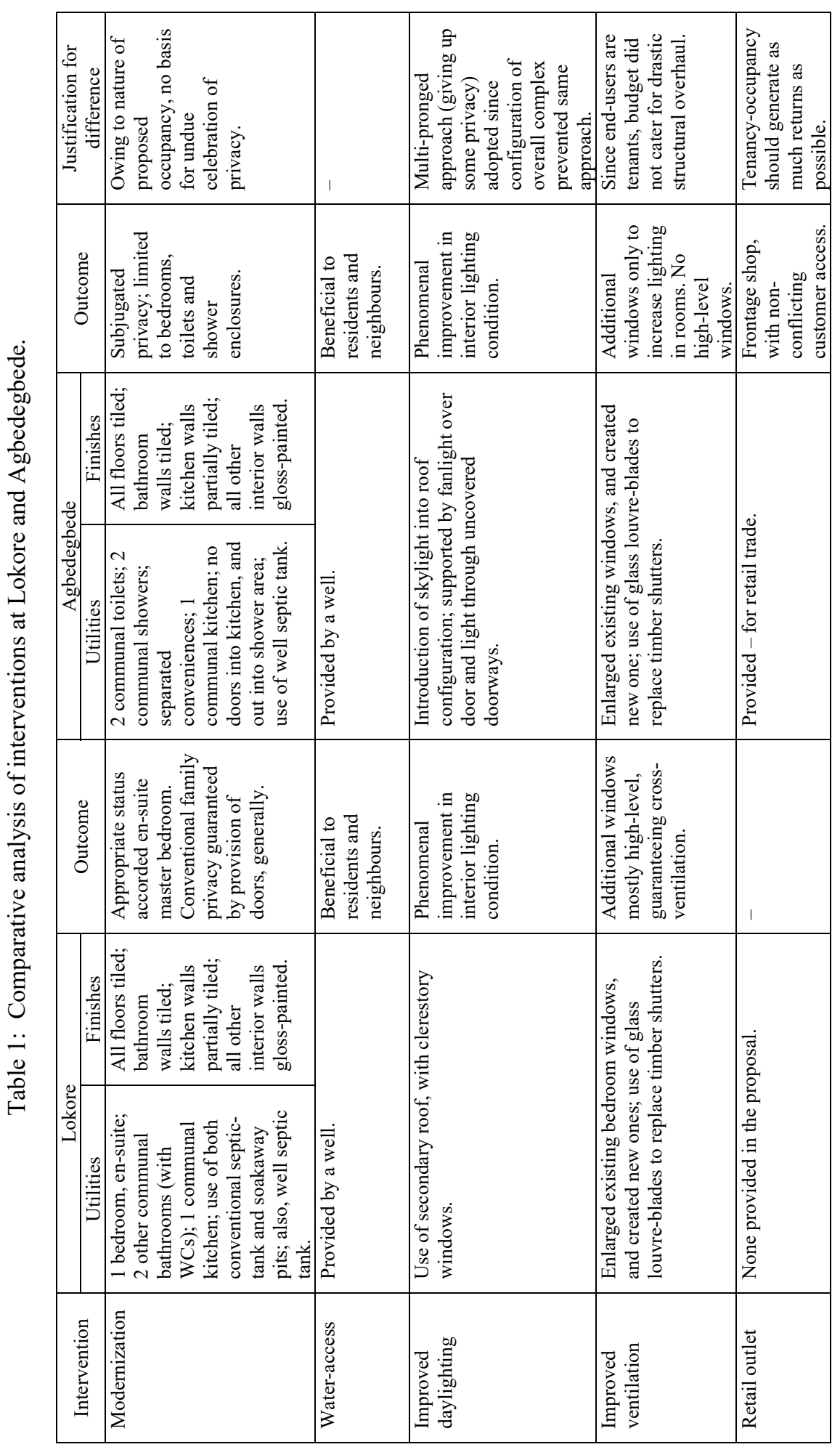




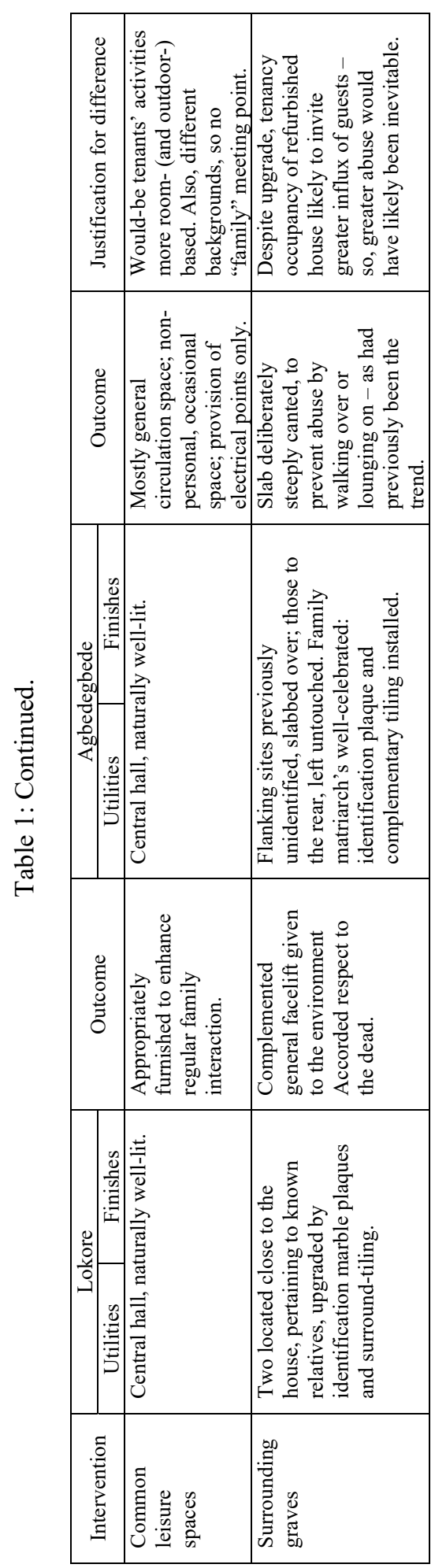


architectural "correctness" or overt aesthetics. This could be deemed necessary, if doing so increased the overall accommodation provided.
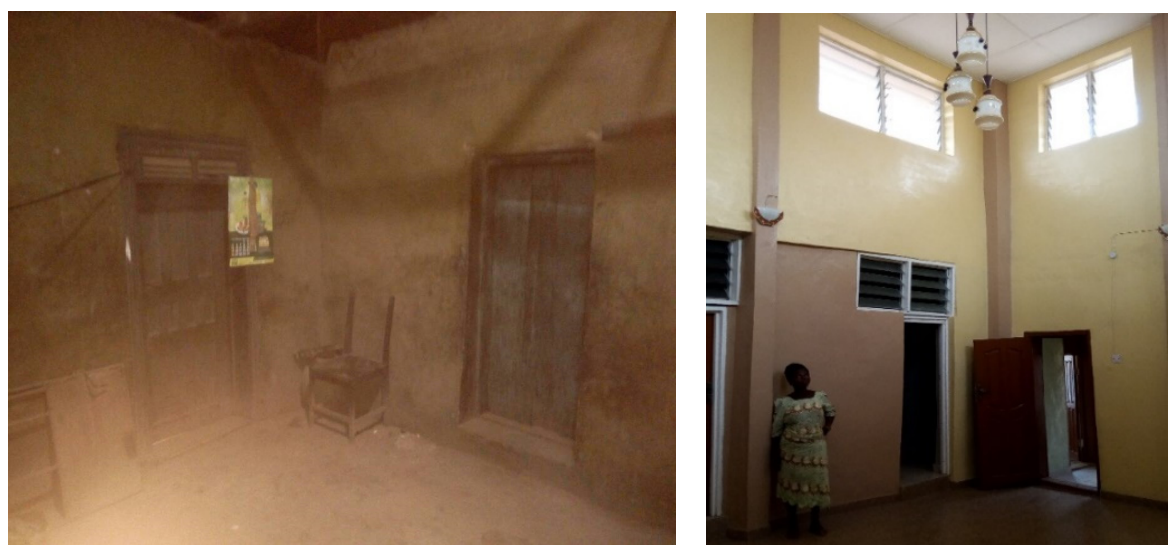

Figure 1: (a) Hall at Lokore house, before renewal; and (b) After renewal; lighting facilitated by clerestory.
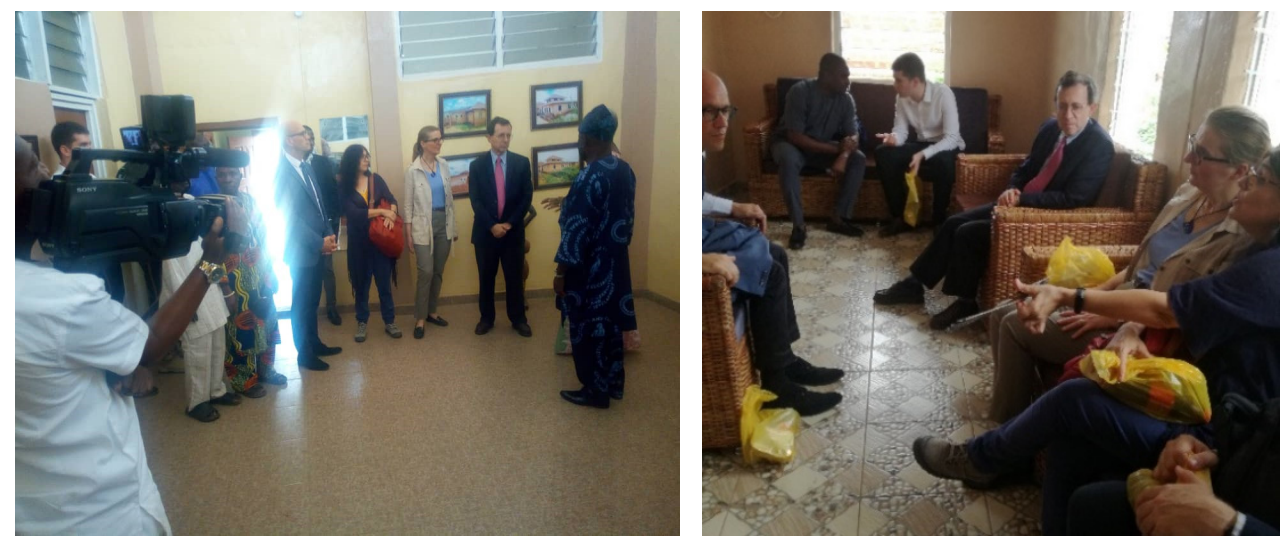

Figure 2: (a) French Ambassador and entourage viewing transformed Hall at Lokore; and (b) Relaxing in the lounge there, after the tour (September 16, 2019).

\section{CONSTRAINTS}

In both cases, the buildings were of cob construction, and over eighty (80) years old. Coupled with this, was the fact that local building practice orientations were adopted (characterised by rule-of-thumb measurements, resulting in visible imprecision). Specifically, most walls were skewed - generally out of alignment with the $90^{\circ}$ angle - while horizontal planes were commonly out of plumb. Also characterising the two buildings, was extended-family constraints on configuration: there was more than one dominant character to dictate the fate of the building. This imposed additional complications on physical extent (and actual handling) of the intervention. A notable feature to be offset in both schemes was the twilightlike darkness defining interior communal space within the buildings. 


\subsection{Peculiar constraints at Agbedegbede}

Agbedegbede is actually the name of the street (On its part, "Lokore" refers to the neighbourhood in which the Odeyemi Family House is located) (Fig. 3). One of the peculiar difficulties encountered in the course of the adaptive reuse intervention at Agbedegbede was the fact that, in addition to implied extended-family complications, there was tacit hostility from those still in residence in the untouched wing of the house. Others were: gross disalignment of walls in the existing building configuration; restrictions for correction imposed by adjoining burial sites of dead family members; general constraining influence of built-up environmental context; neighbourhood hooliganism, and other constraints imposed by sizeable ruins of demolished adjacent structure.

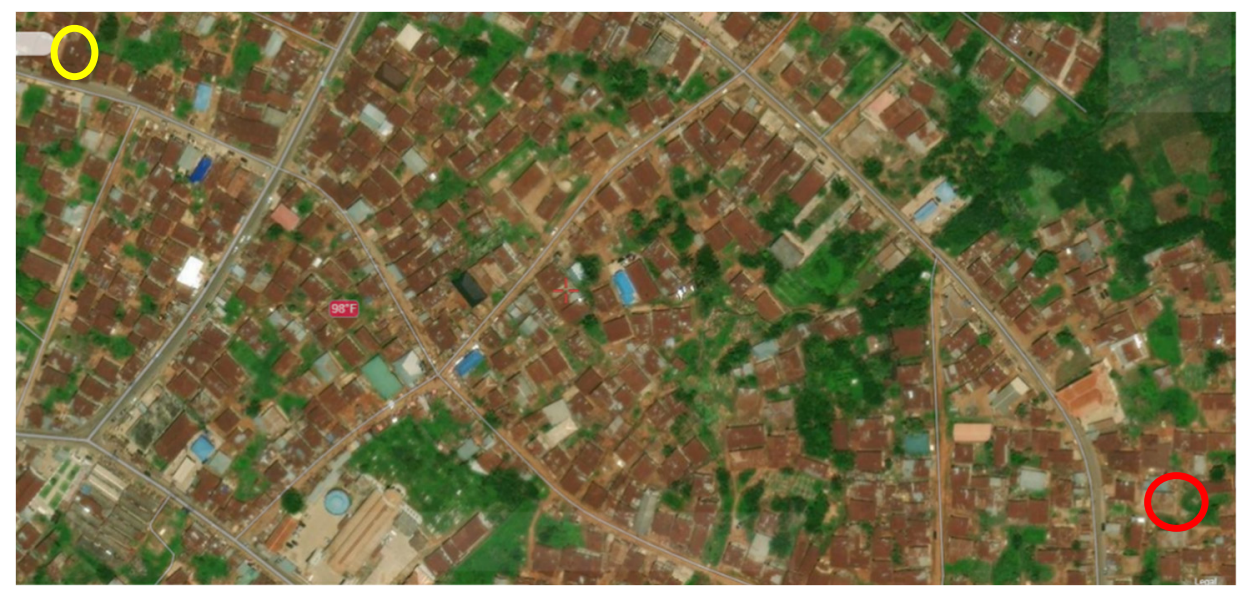

Figure 3: Relative locations of Agbedegbede (upper left, yellow) and Lokore (lower right, red). (Source: Google Maps.)

\section{AGBEDEGBEDE HOUSE BEFORE RENEWAL}

Situated less than a kilometre from the Odeyemi Family House at Lokore (as the crow flies), the Agbedegbede House is in the ancient heart of Ile-Ife; in fact, it is barely half a kilometre from the palace of the Ooni, the traditional monarch. (Interestingly, the traditional family rallying-point of the present ruler, the Giesi akodi, is directly opposite the house). As such, the environment is densely-populated with typical Ifes, steeped in the local culture - up to Lokore and beyond.

Despite the generally decrepit state of the building, it was still partially occupied. Similarly, the surroundings were still in use, though extremely un-complimentarily. On the north-western flank, a huge mound of essentially laterite debris (from the government demolition of a structurally-weakened and dangerous building), dominated the landscape. This formed a massive obstruction to the frontage of the rest of the extended-family accommodation, essentially screening it from the road (see Fig. 3). The north-eastern (rear) side of the building was practically a public latrine. The frontage of the building itself had virtually no setback (as even part of its plinth narrowly missed the rim of the gutter running in front of the house). Abutting this frontage is a grave of the matriarch of the home, Madam Jemilat Ayanlola Hassan-Mosaku; traditionally, this was just routinely slabbed over, with her name scrawled on it. Though perfunctory, it served the purpose of identification of location, 
and according it due recognition. It was common practice for this slab to serve as a safer way to connect with the entrance stairway, much of the lower part of which had been eroded away over time. In addition, it served as a relaxation area for neighbourhood layabouts (who routinely brought plastic seats from a drinking "joint" across the road, and ensconced themselves there). Fig. 4(a) and 4(b) show the frontage of the Agbedegbede House before the renewal exercise. In addition to the public sewer, there is a lamp-post at the front of the house - broken and non-functioning.
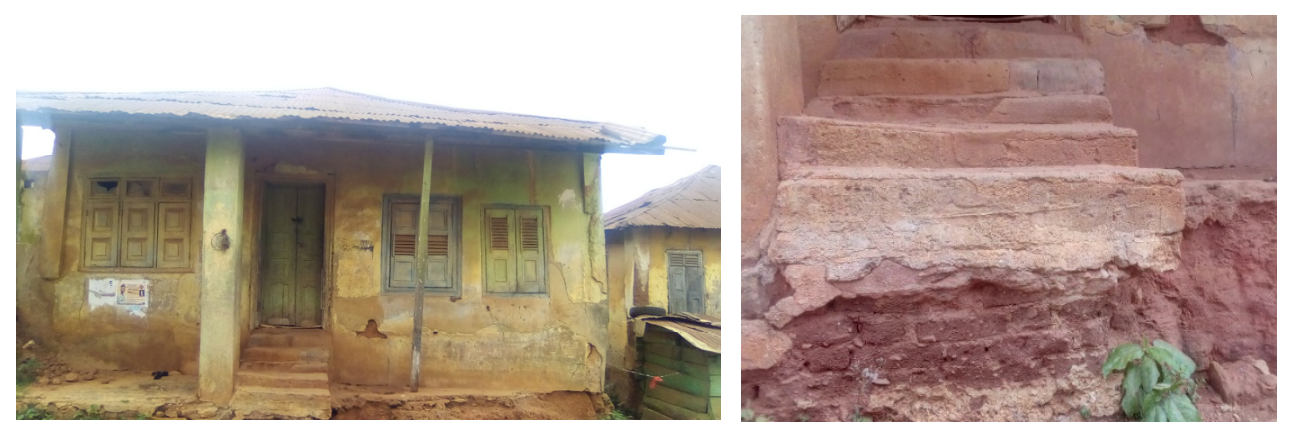

Figure 4: (a) Frontage of Agbedegbede House before renewal; and (b) Close-up of eroded plinth and steps leading into the building, 2020.

\section{WORK UNDERTAKEN AT AGBEDEGBEDE}

In an attempt to renew the house at Agbedegbede (and adapt it for its new intended use) several things needed to be taken peculiarly into consideration. The existing rooms in the house were extremely dingy - most of them significantly less than $9 \mathrm{~m}^{2}$. This informed an immediate resolve to increase room sizes (in spite of the obvious land constraint on the flank of the building indicated for extension). In addition, interior lighting needed to be improved - despite the issue of the barrier imposed by the other adjoining spaces that were not to be tampered with, and a tight budget. There were facilities that had not been previously provided, but non-negotiable, in a "modern building" (such as bathrooms and a kitchen), which needed to be accommodated.

\subsection{The design}

With constraints centred on available site area, general scope of intervention and a lean budget, it was obvious that the proposal would feature only necessary alterations. The design problem was seen as meeting the needs of the major target group (paying tenants), essentially within the confines of the existing building, and to meet modern exigencies. Several initial proposals had to be jettisoned - based on discoveries on site in the process of implementation. (Figs 1, 2 and 4 trace the progression). Reasons for this include the discovery of burial sites on one flank, and a septic tank (under the debris), on another.

At Lokore, the hall (constituting a concourse of sorts) was appropriated as a "bonding space" for family members (see Fig. 5). Though a similar space exists at Agbedegbede, it could not be treated the same way; paying tenants do not necessarily relate with such levels of intimacy. Other spaces of (inevitable) common use (e.g. the kitchen and conveniences) also called for peculiar spatial treatment. On their part, bedrooms are unequivocally places of great privacy and intimacy. 


\subsubsection{Spatial provisions}

In the articulation of the final design (Fig. 4), six of the original seven rooms retain their erstwhile designations: two room-and-parlour suites, and two independent rooms. The seventh has been sub-divided to provide toilets for the house; a common wash-hand basin, located in the entrance lobby, serves the two toilets. Also, in a bid to ensure height clearance of the pipework related to toilet fixtures (with respect to the tombs behind the rear wall), a platform was created in the toilets.

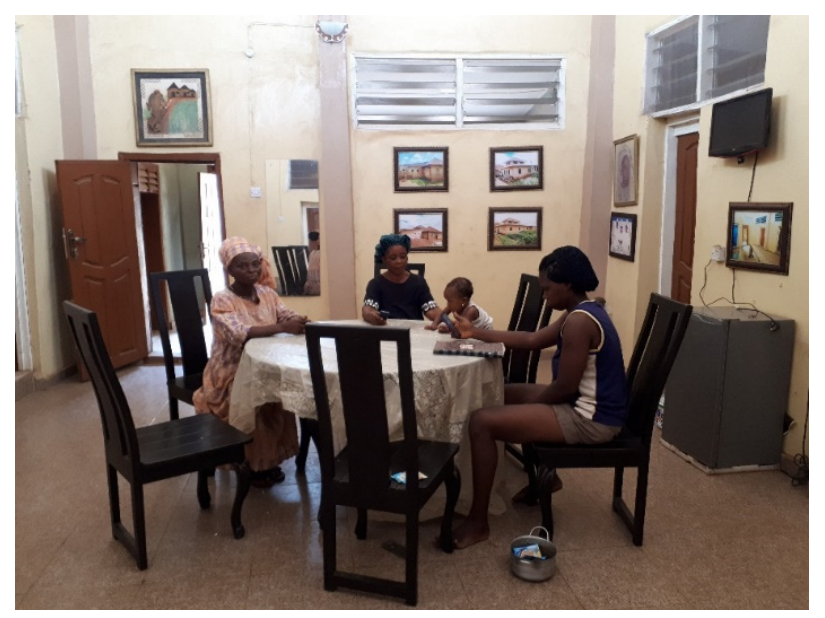

Figure 5: The common hall at Lokore; used for dining and general-family lounging (at $1.25 \mathrm{pm}$, on April 8, 2021).

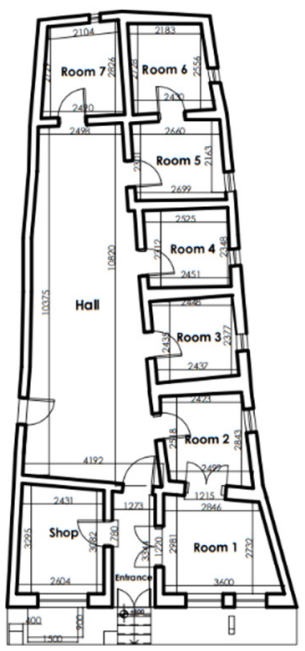

Figure 6: Existing floor layout.

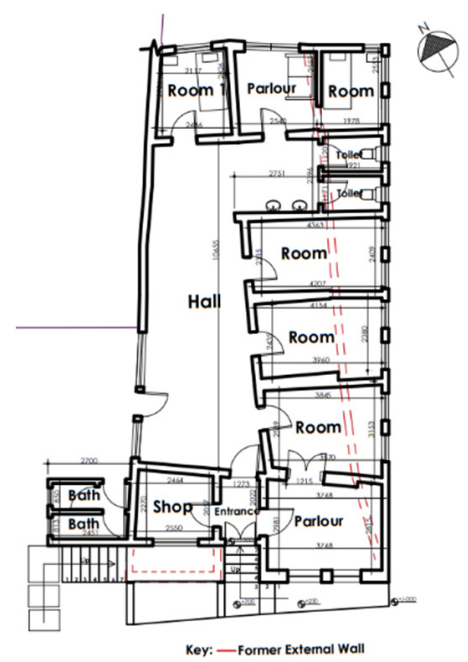

Figure 7: First proposal. 


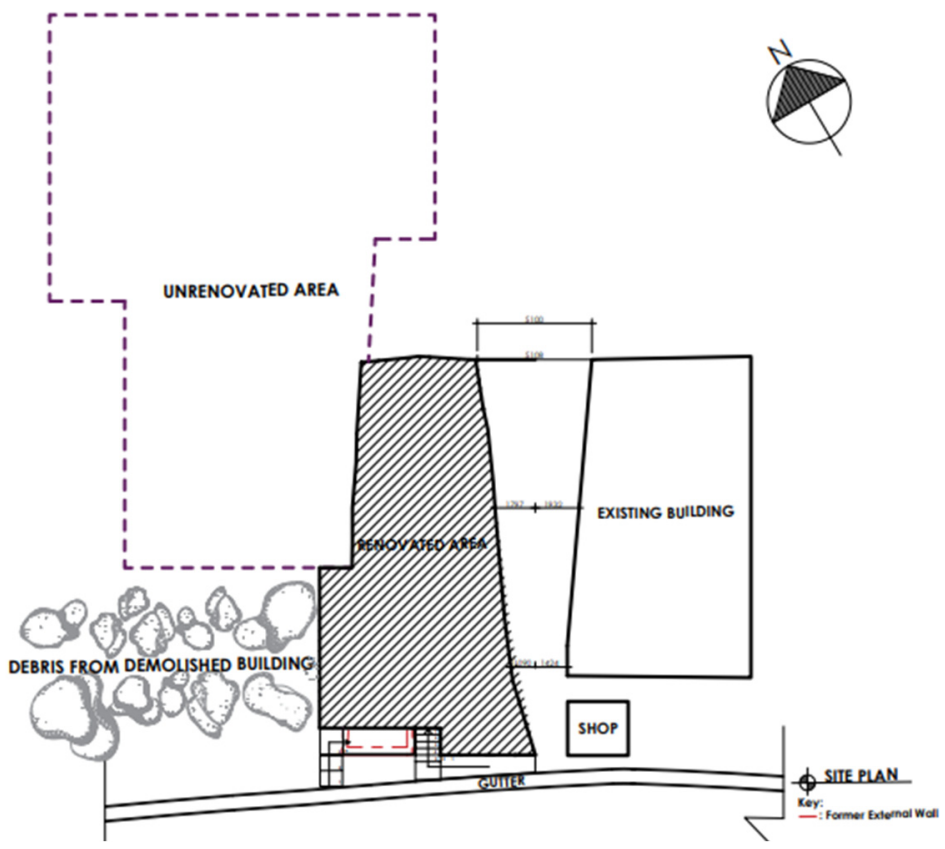

Figure 8: Agbedegbede site layout.

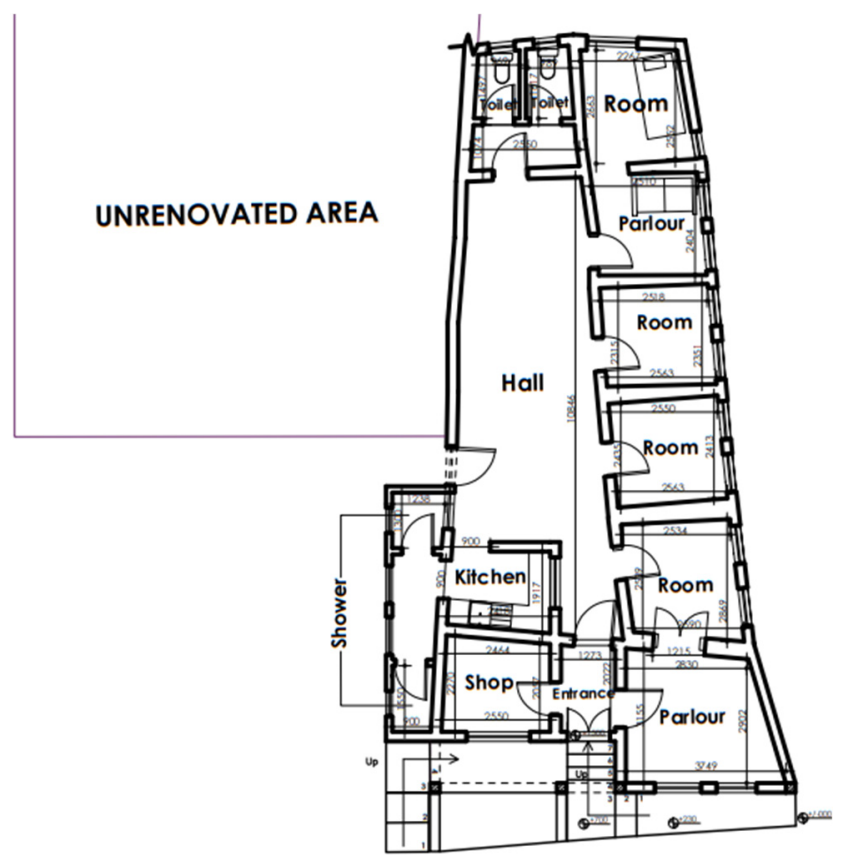

Figure 9: Final proposal, showing separated conveniences: toilets at the rear, showers by the kitchen. 
The common hall is essentially circulation space. However, given the constrained nature of the private rooms, electrical power outlets (4) have been provided here. This is to allow those with refrigerators, freezers, etc. to connect them to the power-source at these points. This, therefore, makes this space also a common service area; however, the onus to secure their refrigeration units lies with tenants using the space for such appliances! Alternatively, the hall can be used for social functions such as child-naming ceremonies, and nominal extended-family meetings, among others (see Fig. 6).

In recognition of the sheer size of this hall needing to be naturally lit (and the fact that the area devoted to sky-lighting would necessarily be limited), the design sought to introduce additional day-lighting from alternative sources. High-level lighting (above the alternative door into the house) was integrated into the design. However, the major supplementary lighting was to be provided from the bathroom area - a new wing added to substantively provide this facility to the residents. To optimise the effectiveness of the fenestration here, doors (into the kitchen, and out from there into the showers) are totally eliminated. This was deemed acceptable as, from the viewpoint of tenants, there is no personal, sentimental attachment to the (communal) cooking area. This understanding also informed even the way shelving has been provided in the kitchen cabinet: nothing of any personal value will ever be actually stored in an all-comers facility.
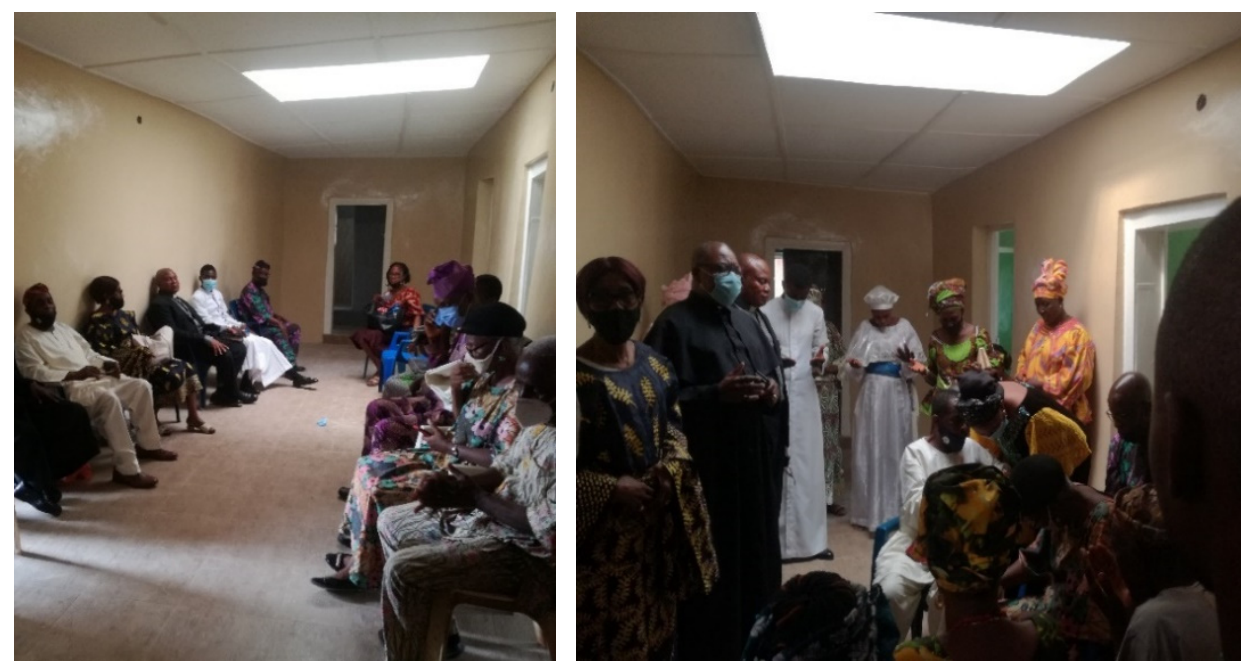

Figure 10: The hall at Agbedegbede, during the formal "opening ceremony". (a) Waiting for the sponsor; note the effectiveness of the skylight; and (b) Special prayers by clergymen (Saturday, April 3, 2021, 3.30 pm).

A shop had been part of the existing design. Strategically positioned at the frontage of the house, it had been a tailor's shop; however, the entrance had been through a side wall - after essentially gaining access into the house, first. As part of the modern-day clear resolution of circulation pattern, this arrangement has been changed (more so as the retail trade is more identified with a home-base, today, than services). As such, prospective customers are restricted to the front of the shop, getting sales attention through a window provided for such, and being physically confined to the veranda from which they interact with the vendor, by a metal grille (see Fig. 11). 


\subsubsection{Cost-control measures}

The mandate to cut costs had been unequivocal. However, the local realities on ground (recession, attendant inflation resulting in galloping prices of building materials), may not have made strict adherence noticeable. While needless spending was certainly not indulged in, professional judgment also dictated the use of durable materials that would offset their initial capital outlay, over a reasonable part of the building's lifespan.

The strategy adopted was to retain whatever was still useful: door-frames, doors, rooftruss members, walls - crooked or otherwise. This has resulted in a motley arrangement of building elements and features. In keeping with the requirement (and to synchronise with the still-dominant existing roof of the rest of the building complex), aluminium sheet-cladding was specified - as opposed to the stone-coated, profiled steel (Gerard) sheets used at Lokore. The former corrugated zinc sheets had, over decades, rusted and assumed a homogeneous brown colour. As such, specifying brown aluminium sheets was clearly indicated.

In the spirit of long-term reduced maintenance costs (and similar to the situation at Lokore), gloss paints were specified for all interior spaces (with tiling in toilets, showers and parts of the kitchen). This was to pre-empt the need for frequent re-painting, based on the sure knowledge that in such communities, casually (and frequently) running hands over wall surfaces is a quite established habit.

With basic floor-tiling (using the sturdy, anti-slip, easy-to-clean tiles presently available on the market), cost-in-use considerations prevailed in the specification. Though not significantly inferior to those employed at Lokore, they are less classy. Generally, going for the same grade as the previous, would certainly have been at a significantly higher cost.

Comparing the expenditure deployed at Lokore to achieve the results obtained, with current prevailing prices would, doubtless, present a conservative mark-up of at least $60 \%$. Even at that, the present scheme has not come drastically cheaper. As such, in absolute terms, the Agbedegbede renewal project has not been achieved within the envisaged "shoe-string budget" scope - for the reasons stated above.

\subsubsection{Expansion of spaces}

Figs 1, 2 and 4 show the progression in attempts at resolving this. Squaring off the right-hand side of the building from the frontage to the rear, automatically enlarged the rooms, six of the existing seven being in this wing. As such, this measure was immediately adopted in the (initial) design proposal. However, as soon as digging up the new foundations for this extension started, work was abruptly stopped by an extended family member. She claimed there were graves in the intervening space between this flank and the building adjacent to it - despite there being no visible evidence at ground level! This notwithstanding, the assertion was soon verified as being true. It resulted in this design being abandoned, and a return to the original constraining walls and undersized spaces. Nevertheless, alternative spaces were created, while some existing ones were re-assigned (see Fig. 4).

\subsubsection{Improved interior lighting}

At Lokore (and with a similar constraint on the renewal not to cover the whole existing building), the course of action to improve daylighting, had been fairly straightforward. However, here, additionally, the client was categorically averse to a general overhaul of the roof to effect this. This was to support his position on not spending "too much" on the project.

Rather than clerestory windows (employed at Lokore, by creating a secondary roofsystem), this mandate was realised by the use of a skylight. Fig. 6 shows its efficacy. 


\section{COMPARATIVE ANALYSIS}

Table 1 looks at specific features both Lokore and Agbedegbede renewal interventions have in common - and where they differ. It also sets out the rationale for these attributes, in light of the respective mandates and enabling designs.

\subsection{Plumbing}

As previously-stated, the Agbedegbede House is seriously cramped, in its physical deployment. In the northeast, neighbours' properties restrict any building activities there more so, as the little intervening space is taken up with (actually celebrated) tombs. The south-eastern flank looked innocuously useful for expansion, though still constrained - until proved to be a no-go area by the existence of unmarked graves. In the southwest, the building virtually sits on the rim of the public sewer; in the northwest, debris prevents any meaningful activity there (in addition to the fact that the land in that area belongs to another family).

With respect to the issue of providing mechanical services to the building, this restriction on all sides has proved a big challenge. The conventional septic-tank/soakaway-pit arrangement could not be invoked; even inspection-chambers had to be ingeniously situated and crafted. However, recourse was made to the use of a combined "well" septic-tanksoakaway pit. The provision of water is currently underway on the northwest flank, close to the alternative entrance to the house; a well is being dug - after successful overtures to hitherto hostile members of the extended family. Since there is no public water utility in the area, this will be a community benefit - just like the one at Lokore is currently being.

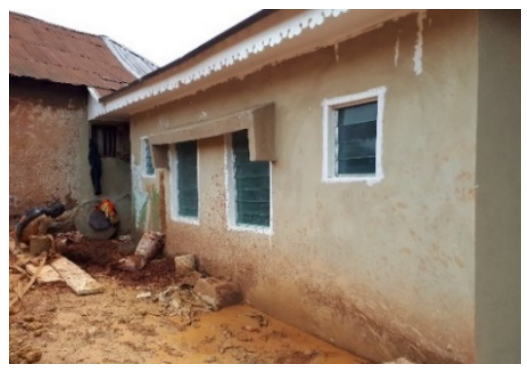

Figure 11: Unpainted north-western flank; ongoing well-works to the left.

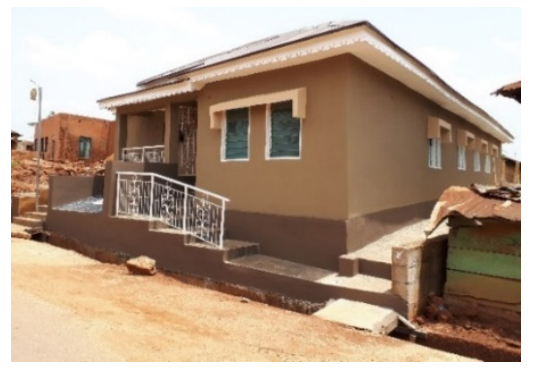

Figure 13: Access to the house, from the Agbedegbede road.

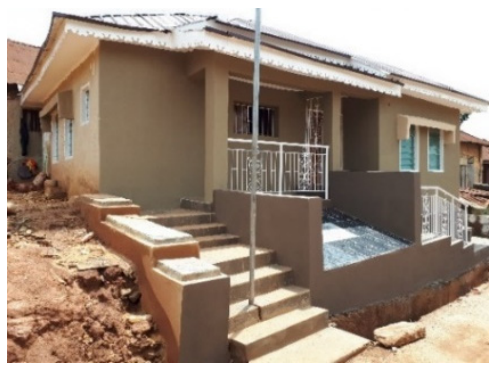

Figure 12: Tomb of matriarch, Madam Hassan-Mosaku, raked to discourage sitting.

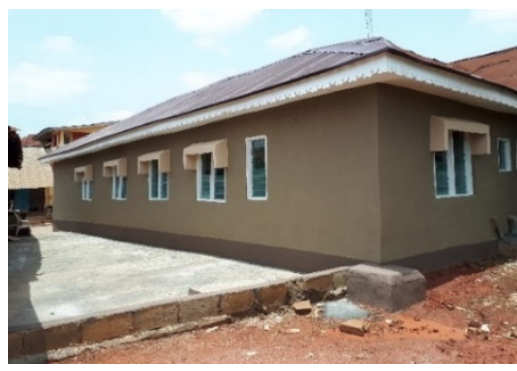

Figure 14: View from the rear. 


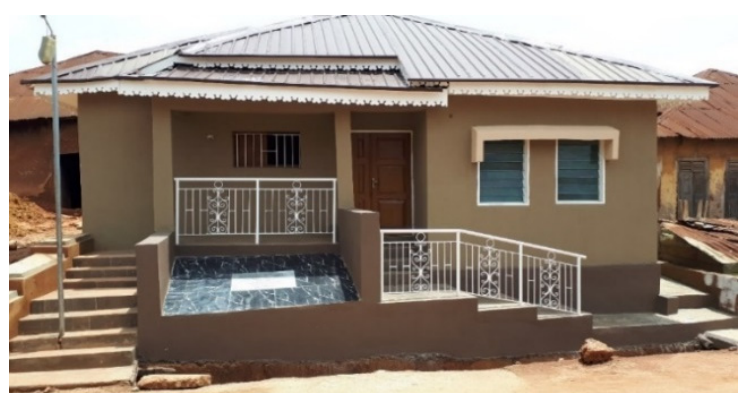

Figure 15: Front façade of Agbedegbede House, after renewal. The stairs to the left lead to the sales veranda; those on the right, lead to the main entrance of the building, April, 2021.

\section{CONCLUSION}

Both the Lokore and Agbedegbede house-renewal schemes had peculiar challenges, even though contexts and mandates were generally similar. The major point of departure was that, whereas the former had family comfort as a priority, the latter was more concerned with practical, utilitarian provisions for paying tenants. This fundamental difference not only dictated spending profile, but also conditioned general design inclinations in articulating the proposal. Figs 7-11 capture the essence of the new-look house at Agbedegbede Street.

As an architectural professional expedient, the purpose to which a building will ultimately be put invariably dictates design orientation. However, for schemes that are typologically the same, similar in environmental and cultural context, sponsored by the same client and handled by the same architect, very few issues should be able to produce significant differences in outcome. Two such obvious conditioners are budget and occupancy.

In the case-studies reviewed, it has been seen that these two factors have significantly inter-played to justify the noticeable differences in the end-results - all other factors having remained the same. Despite the injunction to cut costs as much as possible on the Agbedegbede House project, the predominant factor making the significant difference in design orientation, has been the type of occupancy proposed for the building. As such, it is reasonable to conclude that the nature of eventual occupancy in a residential building is cardinal in determining the proposed initial investment on the building, and the actual eventual design to fit the budget.

\section{REFERENCES}

[1] Harvey, J., Conservation of Buildings, John Baker Ltd.: London, p. 18, 1972.

[2] Osasona, C.O., Nigerian architectural conservation: A case for grassroots engagement for renewal. International Journal of Heritage Architecture, 1(6), p. 15, 2017.

[3] Hardy, M., The Venice Charter Revisited: Modernism, Conservation and Tradition in the $21^{\text {st }}$ Century. Cambridge Scholars Publishing: Newcastle upon Tyne, 2008.

[4] Osasona, C.O., Nigerian architectural conservation: A case for grassroots engagement for renewal. International Journal of Heritage Architecture, 1(6), pp. 4-6, 2017.

[5] Osasona, C.O., Architectural renewal: A rising dawn in Ile-Ife? Proceedings of the 16th STREMAH Conference, pp. 43, 56, 2019.

[6] LEGACY, Historical Sites of Nigeria, LEGACY: Lagos, 1999.

[7] Osasona, C.O., Architectural renewal: A rising dawn in Ile-Ife? Proceedings of the 16th STREMAH Conference, pp. 43-56, 2019. 